\title{
Experimental and Analytical Studies on Compressive Behaviour of Concrete Filled Circular GFRP Tubes
}

\author{
C. Ramesh Babu*, S. Prabavathy and M. Saranya \\ Department of Civil Engineering, Mepco Schlenk Engineering College, Sivakasi - 626005, Tamil Nadu, India; \\ rameshbabu_1979@rediffmail.com,spraba@mepcoeng.ac.in,m.saranyasree@gmail.com
}

\begin{abstract}
Background/Objectives: An extensive experimental and analytical investigation was carried out to explore the behaviour of circular concrete filled GFRP tubes (CFFTs) using NSC (Normal Strength Concrete), HSC (High Strength Concrete) and UHSC (Ultra High Strength Concrete). Methods/Statistical Analysis: The experimental study explored the compressive behaviour of 27 CFFTs having three different diameters 75, 100 and $150 \mathrm{~mm}$ of constant thickness $3 \mathrm{~mm}$. Un confined concrete strength up to $98 \mathrm{MPa}$ was achieved under normal curing conditions. Findings: The research findings prove that adequately confined high strength CFFTs can exhibit highly ductile behaviour and they are highly sensitive to the level of confinement. The GFRP tubes with UHSC infill could not maintain the load carrying capacity after attaining initial peak strengths. A newer methodology using shell elements was adapted for simulation of CFFTs in ANSYS and the results agreed with that of the experimental investigation. Applications/Improvements: The investigation explored that specimen size does not have major influence on strain reduction factor. New values of strength and strain enhancement ratios $\mathrm{K}_{1}$ and $\mathrm{K}_{2}$ has been arrived.
\end{abstract}

Keywords: Analytical, Circular, Concrete, Compressive Behavior, Experimental, GFRP

\section{Introduction}

The concrete filled FRP (Fiber Reinforced Polymer) tubes have been an attraction to the structural and architectural engineers as an alternate to wood, steel and concrete. The concrete being brittle when used with FRP tube as confinement forms an efficient element in corrosive environments. The High Strength Concrete (HSC) and Ultra High Strength Concrete (UHSC) when used with FRP becomes superior high quality materiall offering highly ductile behavior in seismic prone areas. There has been numerous researches on the CFFTs (Concrete filled FRP tubes) used as flexural and compression elements over the past two decades. The available literature concludes that there are more than 200月 experimental studies have been conducted by researchers and none of them is able to predict the behavior accurately. There has been a broader research on post jacketing methodology adopted in concrete filled FRP tubes whereas the pre jacketing methodology of CFFTs deserve further research and this study evaluated the latter one with 27 concrete filled GFRP tubes under concentric compression and finite element modeling of the same.

\section{Theory Behind Behavior of Confined Concrete}

The ACI Code (ACI committee 440, 2002) has codal provisions for defining the confining pressure $\left(f_{c p}\right)$, force generated by the composite, hoop strain $\left(\varepsilon_{\mathrm{f}}\right)$, fracture $\operatorname{strain}\left(\varepsilon_{\mathrm{fu}}\right)$,compressive strength at confining pressure $\left(f_{c c}^{\prime}\right)$ and nominal capacity of the columns. The theory behind these equations is as follows:

$$
f_{c p}=\frac{2 t_{f} f_{f}}{D}
$$

Since $\mathrm{f}_{\mathrm{f}}=\mathrm{n}_{\mathrm{f} f \mathrm{f}} \mathrm{E}_{\mathrm{f}} \varepsilon_{\mathrm{f}}$

$f_{c p}=\frac{2 n_{f} t_{f} E_{f} \varepsilon_{f}}{D}$

If the confining reinforcement ratio $\rho_{\mathrm{f}}$ is expressed as a function of area and diameter, 


$$
\begin{aligned}
& \rho_{f}=\frac{4 n_{f} t_{f}}{D} \\
& f_{c p}=\frac{\rho_{f} E_{f} \varepsilon_{f}}{2}
\end{aligned}
$$

When the expansion of concrete induces sufficient strain on the composite, the composite fractures, leading to the fracture of the concrete. For members subjected to shear and compression, the effective fracture strain of the composite at failure $\varepsilon_{\mathrm{fe}}$, should be limited to a maximum of 0.004 and $0.75 \varepsilon_{\mathrm{fu}}$ or $\varepsilon_{f e}=0.004 \leq 0.75 \varepsilon_{f u}$. Therefore the confining pressure:

$$
f_{c p}=\frac{\rho_{f} \varepsilon_{f} \varepsilon_{f z}}{2}
$$

Based on the experimental results (ACI committee 440, 2002), the compressive strength at this confining pressure,

$\mathrm{f}_{\mathrm{cc}}^{\prime}$ can be expressed as:

$\mathrm{f}_{c c}^{\prime}=\mathrm{f}_{\mathrm{c}}^{\prime}\left[2.25\left(1+7.9 \mathrm{f}_{\mathrm{cp}}^{\prime} / \mathrm{f}_{\mathrm{c}}^{\prime}\right)^{0.5}-2 \mathrm{f}_{\mathrm{cp}} / \mathrm{f}_{\mathrm{c}}^{\prime}-1.25\right]$

The strain corresponding to the peak stress is

$$
\varepsilon_{c c}^{\prime}=\varepsilon_{c}^{\prime}\left[\frac{6 f_{c c}^{\prime}}{f_{c}^{\prime}}-5\right]
$$

where $f_{c}^{\prime}$ and $\varepsilon_{c}^{\prime}$ are the peak compressive stress and corresponding strain for unconfined concrete respectively. If $\varepsilon_{c}^{\prime}$ is not given, it can be estimated using the following equation:

$$
\varepsilon_{c}^{\prime}=1.71 \frac{f_{c}^{\prime}}{E_{c}}
$$

The enhanced compressive strength $\mathrm{f}_{\text {'c }}$, can be used for the computation of the column axial force capacity. A reduction factor $\psi \mathrm{f}$ is recommended for the concrete contribution. The recommended value for $\psi_{\mathrm{f}}$ is 0.95 . For non prestressed member the nominal capacity of a column can be computed using the equations recommended in ACI code (ACI committee 440, 2002).

For a column with spiral reinforcement:

$P_{n}=0.85\left[0.85 f_{c c}^{\prime} \psi_{f}\left(A_{g}-A_{s t}\right)+A_{s t} f_{y}\right]$

For a column with lateral ties:

$$
P_{n}=0.85\left[0.85 f_{c c}^{\prime} \psi_{f}\left(A_{g}-A_{s t}\right)+A_{s t} f_{y}\right]
$$

where $\mathrm{A}_{\mathrm{g}}$ is the cross sectional area of the concrete and $\mathrm{A}_{\mathrm{st}}$ is the area of the longitudinal reinforcement.

\section{Experimental Investigation}

\subsection{Experimental Setup}

The GFRP (Glass Fiber Reinforced Polymer) tubes have been manufactured by wet lay-up methodology and supplied by local manufacturers with winding angle $\pm 85^{\circ}$ Three types of GFRP tubes having internal diameter 75 , 100 and $150 \mathrm{~mm}$ were chosen and a constant of $3 \mathrm{~mm}$ was maintained. The mix design were worked out using silica fumes and Superplasticizer MasterGelnium SKY 8233 along with normal ingredients of concrete to achieve three types of concrete having target strengths ranging from $28 \mathrm{MPa}$ to $98 \mathrm{MPa}$ which have been categorized as Ordinary Concrete (M10 to M20), Standard Concrete (M25 to M55), High Strength Concrete (M60 to M100) and Ultra High Strength Concrete (M100 to M150) as per IS: 10262 - 1982. There were no special curing methodologies adopted and the target strengths of the concrete were achieved under room temperature $\left(32^{\circ}\right)$ prevailed in the lab atmosphere by normal curing. The interior of the GFRP tubes were roughened with emery paper and then the concrete was poured and the CFFTs were cast. The specimens were test in $1000 \mathrm{KN}$ capacity UTM. For each configuration 3 specimens were tested for consistency. The investigation explored the effects of nominal confinement ratio, the structural response, integrity and effectiveness of the GFRP tube confinement. The stress strain curves and stress vs. displacement curves were directly obtained by from the computerized UTM. Since this was a preliminary trial study, the expressions for confining pressure, confined strength, strength enhancement ratio, strain enhancement ratio have been calculated using the expressions available in ACI 440.2R - 08. Also finally FEA modeling was worked out and the simulations agree with the experimental values. The figure 1 represents the deflection pattern observed in the lab showing the delamination of the GFRP tube for the UHSC infill. 


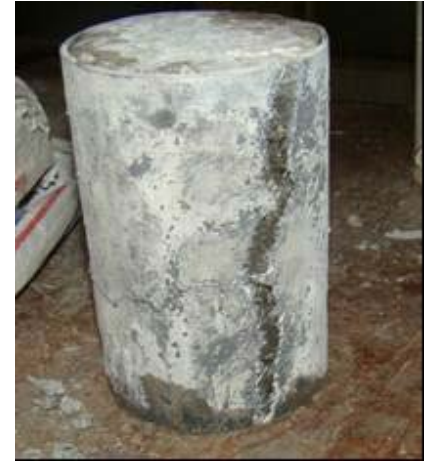

Figure 1. Failure Pattern observed in Lab.

\subsection{Materials used}

Cement: The cement used in all mixture was commercially available Ordinary Portland Cement (OPC) of 43 grade confirmed to IS: 8112-1989. The initial and final setting times were found as 80 and 453 minutes respectively.

Fine Aggregate: Locally available Natural River sand of size below $4.75 \mathrm{~mm}$ confirming to zone II of IS 3831970 is used as Fine aggregate. The Laboratory tests were conducted for fine aggregate to determine its physical properties as IS: 2386 ( Part III ).

Coarse Aggregate: Coarse aggregate used in this study consist of crushed stone of size $12 \mathrm{~mm}$ and below. Laboratory tests were conducted on coarse aggregate to determine the different physical properties as per IS: 383 1970.

Silica Fume: Silica Fume is a by-product of electric arc furnace used for the production of silicon metal or alloy, having specific gravity of 2.2 and bulk density of $720 \mathrm{~kg} /$ $\mathrm{m}^{3}$.

Fiber tubes: FIBRE REINFORCED POLYMER tubes with diameter of $75 \mathrm{~mm}, 100 \mathrm{~mm}$ and $150 \mathrm{~mm}$ with constant thickness of $03 \mathrm{~mm}$ and with the winding angle of 85 degrees. The properties of GFRP tubes supplied by the manufacturers are available in table 1.

Table 1. Properties of GFRP tubes

\begin{tabular}{lccc}
\hline Material & $\begin{array}{c}\text { Tensile Strength } \\
(\mathrm{MPa})\end{array}$ & $\begin{array}{c}\text { Tensile Mod- } \\
\text { ulus }(\mathrm{GPa})\end{array}$ & $\begin{array}{c}\text { Density } \\
\left(\mathrm{g} / \mathrm{cm}^{3}\right)\end{array}$ \\
\hline Glass Fibre & 1600 & 75 & 2.3 \\
\hline
\end{tabular}

Super plasticizers: Master Glenium SKY 8233 is an admixture of a new generation based on modified polycarboxylic ether. Conplast SP430 is based on Sulphonated Naphthalene Polymer and supplied as brown liquid instantly dispersible in water, having specific gravity of 1.220 to $1.225 @ 30^{\circ} \mathrm{C}$.

\section{Finite Element Modeling}

The concrete has been simulated using SOLID 65 element followed by GFRP tubes using MEMBRANE 41 element. After meshing the concrete and GFRP tubes, the nodes were merged and thus the delamination effect of GFRP tubes have been neglected. The SOLID 65 element has the following properties: $E_{c}=5000 \sqrt{f_{c k}}$;

$$
\mu=0.20 \text { and } f_{t}=0.7 \sqrt{f_{c k}} \text {. }
$$

The Open Shear Transfer Coefficient and Closed Shear Transfer Coefficient have been taken as 0.20 and 0.30 respectively after a large number of iterations. The experimental load was applied to the simulations and the results agreed with that of the experimental values. The Vonmises stress plot is represented in figure 2. The figure 3 represents the loads and constraints applied to the CFFTs. The deflection pattern is represented in figure 4.

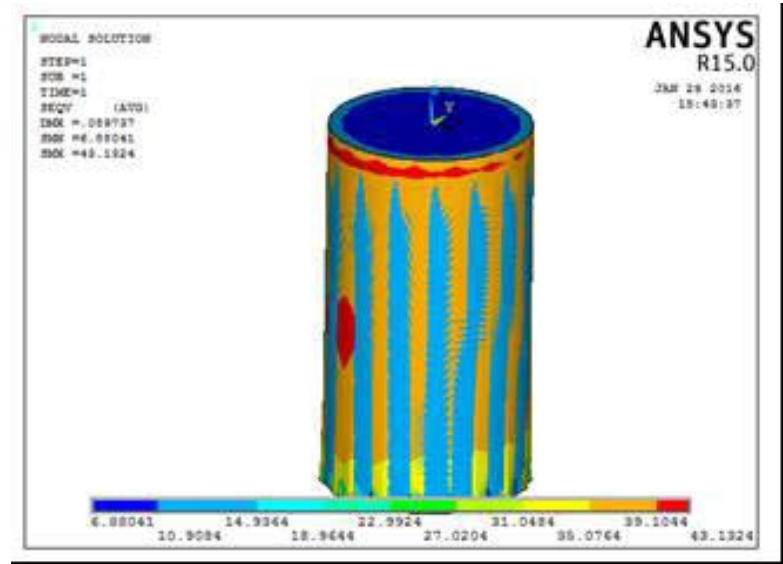

Figure 2. Vonmises Stress Plot.

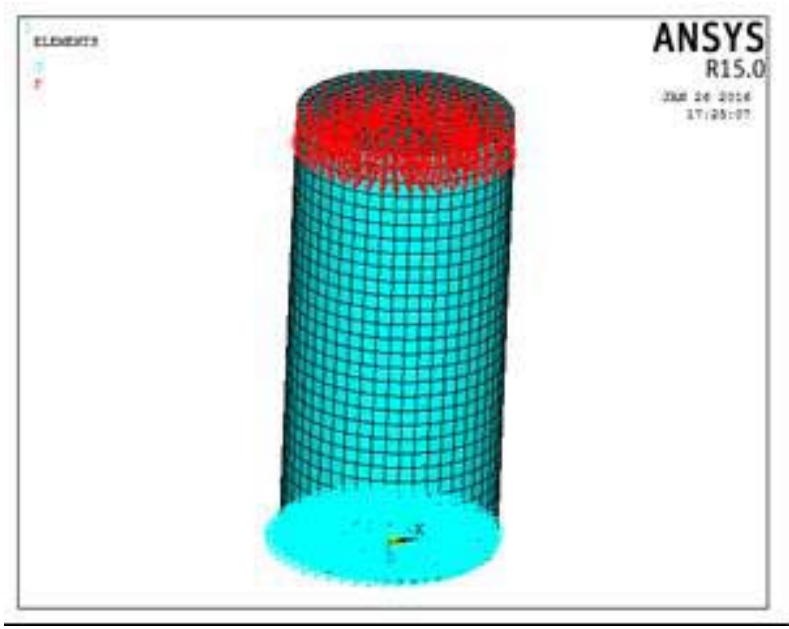

Figure 3. Loads and Constraints. 


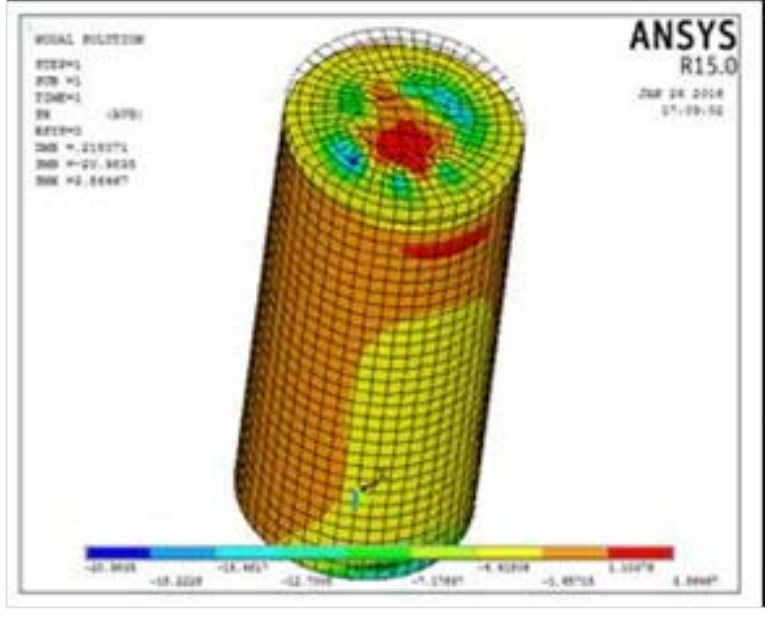

Figure 4. Deflection pattern.

The test results of the FEA modeling is tabulated in table 4 .

\section{Conclusions}

- This investigation presented the results of the trial study carried out on the axial compressive behavior of the concrete filled GFRP tubes manufactured by wet layup methodology. The GFRP tubes were found to be feasible when compared with the research studies made by various researchers.

- From the table 2, it could be observed that the specimen size does not have much influence in the strain reduction factor $\mathrm{K}_{\varepsilon}$. Also there are not many variations in the strain reduction factor due to the concrete strength (say it can be NSC, HSC or UHSC).

- An increase in unconfined concrete strength $f_{c o}^{\prime}$ caused overall decrease both in the strength enhancement ratio $\left(\mathrm{f}_{\mathrm{cc}} / \mathrm{f}_{\mathrm{co}}^{\prime}\right)$ and strain enhancement ratio $\left(\frac{\varepsilon_{c u}}{\varepsilon_{c o}}\right)$. This could be attributed to the increased brittleness with increasing concrete strength which alters the crack pattern from heterogenic micro cracks to localized macro cracks

- An assessment of the influence of concrete strength on the ultimate conditions of CFFT specimens are presented in Table 3 where $\mathrm{k}_{1}$ and $\mathrm{k}_{2}$ are compared. The results conclude that the axial strength and strain enhancement ratios ( $\mathrm{f}_{\mathrm{cc}}^{\prime} / \mathrm{f}_{\mathrm{co}}^{\prime}$ and $\varepsilon_{\mathrm{cu}} / \varepsilon_{\mathrm{co}}$ ) of the CFFTs decrease with increase in concrete strength.

Table 3. Strength $\left(\mathrm{k}_{1}\right)$ and Strain Enhancement $\left(\mathrm{k}_{2}\right)$ Coefficients

\begin{tabular}{lccc}
\hline Size $(\mathrm{mm})$ & Concrete & $\mathrm{K}_{1}$ & $\mathrm{~K}_{2}$ \\
\hline $075 \times 150$ & NSC & 3.57 & 8.78 \\
$100 \times 200$ & HSC & 3.08 & 7.99 \\
$150 \times 300$ & UHSC & 2.52 & 7.45 \\
$075 \times 150$ & NSC & 3.67 & 8.49 \\
$100 \times 200$ & HSC & 3.16 & 7.91 \\
$150 \times 300$ & UHSC & 2.97 & 7.03 \\
$075 \times 150$ & NSC & 3.88 & 7.67 \\
$100 \times 200$ & HSC & 3.10 & 6.98 \\
$150 \times 300$ & UHSC & 2.73 & 5.64 \\
\hline
\end{tabular}

- The influence of the concrete compressive strength on the strain reduction factor $\mathrm{K}_{\varepsilon}$ was examined for comparable GFRP - confined CFFTs. The results prove strong correlation between $\mathrm{K}_{\varepsilon}$ and $\mathrm{f}_{\text {co }}^{\prime}$ in GFRP confined CFFTs. Also this comparison proves that the strain reduction factor $\mathrm{K}_{\varepsilon}$ decreases as the concrete strength increases.

- The adequately confined HSC filled GFRP tubes exhibited highly ductile behavior. However the behavior of these CFFTs is highly sensitive to the

Table 2. Test Results of Concrete Filled GFRP Tubes

\begin{tabular}{|c|c|c|c|c|c|c|c|c|c|c|c|c|}
\hline Group & $\begin{array}{c}\text { Size } \\
\text { (Dia mm) }\end{array}$ & $\mathrm{f}_{\text {co }}^{\prime} \mathrm{MPa}$ & $\varepsilon_{\mathrm{co}} \%$ & $t_{f} m m$ & $\mathrm{f}_{\mathrm{lu}} / \mathrm{f}_{\mathrm{co}}^{\prime}$ & $\mathrm{f}_{\mathrm{lu}, \mathrm{a}} / \mathrm{f}_{\mathrm{co}}^{\prime}$ & $\mathrm{f}_{\mathrm{cc}}^{\prime} \mathrm{MPa}$ & $\varepsilon_{\mathrm{cu}} \%$ & $\varepsilon_{\mathrm{h}, \mathrm{ru}}$ & $\mathrm{f}_{c c}^{\prime} / f_{c o}^{\prime}$ & $\varepsilon_{\mathrm{cu}} / \varepsilon_{\mathrm{co}}$ & $\overline{\mathrm{K}_{\varepsilon}}$ \\
\hline \multirow[t]{3}{*}{ NSC } & 075 & 34.8 & 0.21 & 3 & 0.32 & 0.29 & 228 & 0.63 & 0.07 & 6.55 & 0.72 & 0.67 \\
\hline & 100 & 40.2 & 0.23 & 3 & 0.39 & 0.39 & 308 & 0.80 & 0.91 & 7.66 & 3.50 & 0.89 \\
\hline & 150 & 43.8 & 0.24 & 3 & 0.42 & 0.47 & 348 & 1.06 & 1.02 & 7.94 & 6.10 & 0.74 \\
\hline \multirow[t]{3}{*}{ HSC } & 075 & 61.4 & 0.25 & 3 & 0.89 & 0.49 & 420 & 1.23 & 1.06 & 6.84 & 6.72 & 0.87 \\
\hline & 100 & 64.6 & 0.26 & 3 & 0.62 & 0.52 & 440 & 1.68 & 1.18 & 6.81 & 7.50 & 0.77 \\
\hline & 150 & 68.2 & 0.26 & 3 & 0.68 & 0.54 & 540 & 1.95 & 1.21 & 7.91 & 8.07 & 0.34 \\
\hline \multirow[t]{3}{*}{ UHSC } & 075 & 131 & 0.32 & 3 & 0.84 & 0.58 & 410 & 2.10 & 1.26 & 3.12 & 8.10 & 0.64 \\
\hline & 100 & 146 & 0.33 & 3 & 0.87 & 0.61 & 448 & 2.58 & 1.28 & 3.06 & 8.00 & 0.56 \\
\hline & 150 & 158 & 0.33 & 3 & 0.88 & 0.64 & 620 & 2.7 & 1.3 & 3.92 & 8.18 & 0.57 \\
\hline
\end{tabular}


level of confinement and lightly confined HSCFFTs could not maintain their load carrying capacity after achieving their initial peak strengths.

- For the given nominal confinement $\operatorname{ratios}\left(\frac{f_{l y}^{\prime}}{f_{c o}^{\prime}}\right)$ as observed in table 2, an increase in concrete compressive strength and associated brittleness, leads to overall decrease in the strength enhancement ratio, strain enhancement ratio and the strain reduction factor.

- The finite element modeling predicted approximate results as the de - bonding behavior of the GFRP tubes were neglected. The deformation pattern observed in the FEA modeling agrees with the failure mode of the concrete filled GFRP tubes observed in the lab which has been shown in figure 1 .

Table 4. Test Results of Finite Element Modeling

\begin{tabular}{lccc}
\hline Specimen & Concrete Type & f'co $(\mathrm{MPa})$ & $\boldsymbol{\varepsilon}_{\mathrm{cu}}$ \\
\hline $75 \times 150$ & NSC & 28 & 0.001455 \\
$75 \times 150$ & HSC & 53 & 0.001646 \\
$75 \times 150$ & UHSC & 98 & 0.001273 \\
$100 \times 200$ & NSC & 28 & 0.003379 \\
$100 \times 200$ & HSC & 53 & 0.003314 \\
$100 \times 200$ & UHSC & 98 & 0.002562 \\
$150 \times 300$ & NSC & 28 & 0.000687 \\
$150 \times 300$ & HSC & 53 & 0.000679 \\
$150 \times 300$ & UHSC & 98 & 0.000770 \\
\hline
\end{tabular}

\section{Acknowledgements}

The author would like to thank Mepco Schlenk
Engineering College, Sivakasi for providing Lab facilities and also Fibre tuff Products India Pvt. Limited (Rasipuram), Tamil Nadu, India who manufactured the GFRP tubes used for this research.

\section{References}

1. Ozbakkaloglu T, Saatcioglu M. Seismic behavior of high-strength concrete columns confined by fiber reinforced polymer tubes. J Compos Construct ASCE 2006; 10(6):538-49.

2. Mohamed HM, Masmoudi R. Axial Load capacity of Concrete - Filled FRP tube Columns: Experimental versus Theoretical Predictions. Journal of Composites for Construction. 2010 Apr; 231-43.

3. Ozbakkaloglu T. Behavior of Square and Rectangular Ultra High Strength Concrete filled FRP tubes under axial compression. Composites Part B: Engineering. 2013; 97-111. 